\title{
A raça Indubrasil no Nordeste brasileiro: melhoramento e estrutura populacional $^{1}$
}

\author{
Paulo Luiz Souza Carneiro², Carlos Henrique Mendes Malhado², Raimundo Martins Filho ${ }^{3}$, \\ Antonio Policarpo Souza Carneiro ${ }^{4}$, Fabyano Fonseca e Silva ${ }^{4}$, Robledo de Almeida Torres ${ }^{4}$ \\ 1 Pesquisa financiada pela UESB, FAPESB e CNPq. \\ 2 Universidade Estadual do Sudoeste da Bahia. \\ ${ }^{3}$ Universidade Estadual do Ceará. \\ ${ }^{4}$ Universidade Federal de Viçosa.
}

RESUMO - Com o intuito de fornecer subsídios para programas de melhoramento, conservação e expansão da raça Indubrasil do Nordeste brasileiro, avaliaram-se o histórico evolutivo, as estimativas de parâmetros genéticos e a estrutura populacional da raça. Foram utilizadas informações do pedigree de animais nascidos no período de 1964 a 2006 e dados dos pesos ajustados aos 205, 365 e 550 dias de idade de bovinos nascidos a partir de 1976. As estimativas dos coeficientes de herdabilidade foram menores que as encontradas na literatura para os pesos ajustados nas três idades (P205: direta 0,11 \pm 0,03 e materna 0,01 \pm 0,03; P365: direta 0,16 \pm 0,04 e P550: direta 0,15 \pm 0,05) e os ganhos genéticos para as características decresceram no período avaliado (P205: -0,028 kg/ano; P365: -0,030 kg/ano e P550: -0,025 kg/ano). A baixa variabilidade genética e o ganho genético negativo provavelmente devem-se à redução do tamanho efetivo e ao aumento da endogamia nesse período. Além disso, a redução significativa no número de nascimentos por ano e a pouca utilização de reprodutores externos nos rebanhos colocam a raça Indubrasil do Nordeste brasileiro como um grupo genético sob risco de extinção, fato que sugere a necessidade de programas visando sua conservação e expansão.

Palavras-chave: endogamia, ganho genético, intervalo de geração, tamanho efetivo, tendência genética

\section{The Indubrasil breed in the Brazilian Northeast: breeding and population structure}

\begin{abstract}
In order to provide knowledge for breeding, conservation programs and expansion policies of the Indubrasil breed from northeastern Brazil, the evolutionary history, estimates of genetic parameters and the populational structure of the breed were studied. Pedigree information was used from animals born from 1964 to 2006 and the adjusted weights at 205, 365 and 550 days of age of bovines born from 1976 onwards. The heritability coefficient estimates were lower than those reported in the literature for the adjusted weights at the three ages (P205: direct $0.11 \pm 0$,03 and maternal $0.01 \pm 0.03$; P365: direct $0.16 \pm 0.04$ and P550: direct $0.15 \pm 0.05$ ) and the genetic gains for the evaluated traits decreased in the sampled period (P205: -0.028 kg/year; P365: -0.030 kg/year and P550: -0.025 kg/year). The low genetic variability and the reduced genetic gains were probably due to a reduction in the effective size and increasing inbreeding within the period. Furthermore, the drastic reduction in the number of births per year and the low use of unrelated sires within the herds make the Indubrasil breed a genetic group potentially threatened by extinction, so that conservationist and expansion programmes should be set up.
\end{abstract}

Key Words: effective size, generation interval, genetic gain, genetic trend, inbreeding

\section{Introdução}

A raça Indubrasil surgiu no triângulo Mineiro nas primeiras décadas do século passado, como resultado, principalmente, do cruzamento entre as raças Gir e Guzerá, mas também com participação de outras raças importadas da Índia, como o Ongole, Hissar, Mewati e Sindi(Santiago, 1986).

Atualmente, técnicas de genética molecular têm sido utilizadas para o estudo de populações de animais domésticos (Curi \& Lopes, 2002; Postiglioni et al., 2002; Machado et al., 2003; Spritze et al., 2003; Rangel et al., 2004; Serrano et al., 2004; Egito et al., 2005; Carneiro et al., 2007a; Egito et al., 2007a,b). Entretanto, as informações de pedigree continuam sendo muito importantes e inúmeros estudos para avaliar a endogamia, o tamanho efetivo, a diversidade genética e diversos outros parâmetros populacionais importantes (Faria et al., 2001a, b; Faria et al., 2002; Vercesi Filho et al., 2002a; 
Vercesi Filho et al., 2002b; Nomura et al., 2001; Faria et al., 2004; Cleveland et al., 2005; Parland et al., 2007; Carolino \& Gama, 2008; Malhado et al., 2008a; Martínez et al., 2008). A informação de pedigree para os estudos populacionais tem a vantagem do baixo custo e da simplicidade de obtenção em comparação ao uso de marcadores moleculares.

Alguns simples parâmetros populacionais, largamente dependentes do manejo e dos sistemas de acasalamento, têm grande impacto na variabilidade genética da população. Além disso, os estudos da estrutura das populações podem definir importantes circunstâncias que afetam o histórico genético das populações (Valera et al., 2005).

Em populações comerciais, outra preocupação é com o monitoramento do progresso genético. De acordo com Euclides Filho et al. (2000), o conhecimento da evolução genética de uma população é importante não só para proceder aos ajustes necessários, mas também para que se avalie o resultado do programa de seleção adotado.

No Brasil diversos estudos têm sido realizados com as raças zebuínas a fim de avaliar o progresso genético para características de desenvolvimento ponderal (Oliveira et al., 1995, Euclides Filho et al., 2000, Ferraz Filho et al., 2002; Malhado et al., 2005a,b; Malhado et al., 2008b). O estudo conjunto do progresso genético e da estrutura populacional por meio de informações de pedigree é importante para se entender o histórico do melhoramento das raças e para nortear ações futuras que permitam alcançar maiores ganhos genéticos.

Dessa forma, o objetivo neste trabalho foi avaliar o histórico evolutivo da raça Indubrasil do Nordeste brasileiro, via estudo de tendência genética, estimativa de parâmetros genéticos e estrutura populacional, no intuito de fornecer subsídios para programas de melhoramento genético, conservação e expansão da raça.

\section{Material e Métodos}

Neste trabalho foram utilizados dados do controle de desenvolvimento ponderal da raça Indubrasil, da Associação Brasileira dos Criadores de Zebu (ABCZ). Utilizaram-se informações de pedigree de animais nascidos no período de 1964 a 2006 e dados dos pesos ajustados, pela ABCZ, aos 205 (P205), 365 (P365) e 550 (P550) dias de idade de bovinos nascidos a partir de 1976, no Nordeste brasileiro (Tabela 1).

Para se obterem as estimativas de covariância genética e a predição dos valores genéticos, empregou-se a metodologia da Máxima Verossimilhança Restrita Livre de Derivada, por meio de modelos animais unicaracterísticas, usando o aplicativo Multiple Traits Derivate Free Restrict Maximum Likelihood (Boldman et al., 1995). Para os pesos ajustados aos 205 (P205) dias de idade, foi utilizado um modelo com efeito aleatório genético direto e materno, e de ambiente permanente materno, a covariável idade da vaca ao parto (efeito linear e quadrático), além do efeito fixo de grupo de contemporâneos, admitindo a covariância entre os efeitos genético direto e materno como nula. Para P365 e P550, foi considerado um modelo semelhante ao descrito anteriormente, porém sem os efeitos genético materno e de ambiente permanente materno.

Os grupos de contemporâneos foram constituídos por animais do mesmo sexo, época (estação e ano de nascimento), rebanho e regime alimentar. Grupos de contemporâneos com menos de três animais foram excluídos das análises. Para os pesos P205, P306 e P550, foram formados 882, 641 e 633 grupos de contemporâneos com 6.980, 4.749 e 3.188 pesagens por grupo (Tabela 1 ).

As estimativas das tendências genéticas e fenotípicas para as características foram obtidas pela regressão linear ponderada da média da variável dependente (valores genéticos e pesos observados) sobre o ano de nascimento, por meio do SAS (1999).

Utilizou-se a regressão não-paramétrica por meio de polinômios articulados (spline) para descrever as tendências observadas nos gráficos (Reinsch, 1967). A regressão spline é um tipo de função polinomial cujos segmentos são unidos por nós e cujas derivadas de maior ordem são não nulas e possibilitam, a partir dos dados, a obtenção da curva de regressão. Métodos baseados na regressão spline podem ser verificados em Berry et al. (2002) e Ganguli et al. (2005).

O estimador spline é determinado por:

$$
S(\lambda)=\frac{1}{3} \sum_{i=1}^{n}\left(y_{i}-\hat{f}_{\lambda}(x)\right)^{2}+\lambda \int_{-\infty}^{\infty}\left(\hat{f}_{\lambda}(x)\right)^{2} d x
$$

em que $\hat{f}_{\lambda}$ pertence ao conjunto das funções continuadamente diferenciadas, com derivadas de segunda ordem

Tabela 1 - Estrutura de dados no arquivo analisado para as três características de bovinos da raça Indubrasil do Nordeste brasileiro

\begin{tabular}{lccc}
\hline & P205 & P365 & P550 \\
\hline $\mathrm{N}^{\circ}$ de pesagens totais & 8583 & 6260 & 4181 \\
$\mathrm{~N}^{\circ}$ de pesagens utilizadas & 6980 & 4749 & 3188 \\
$\mathrm{~N}^{\circ}$ de animais na matriz de parentesco & 11074 & 7836 & 5517 \\
$\mathrm{~N}^{\circ}$ de grupos de contemporâneos & 882 & 641 & 633 \\
$\mathrm{~N}^{\circ}$ de touros & 454 & 386 & 378 \\
$\mathrm{~N}^{0}$ de fazendas & 50 & 36 & 36 \\
\hline
\end{tabular}

P205, P365 e P550: pesos ajustados aos 205, 365 e 550 dias de idade, respectivamente. 
de integráveis quadradas; $\lambda$ é uma constante positiva; $S(\lambda)$ é o estimador de alisamento spline, que ajusta um polinômio cúbico em cada intervalo entre pontos.

O $\lambda$ é o parâmetro de alisamento que controla a troca entre a bondade (goodness) e o alisamento (smoothing) do ajuste. Seleciona-se um parâmetro de alisamento $\lambda$ por especificar uma constante c na fórmula $\lambda-(Q / 10) 3 c$, em que Q é o intervalo interquartílico. Esta fórmula faz com que c seja independente da unidade de $\mathrm{x}$.

O software ENDOG (Gutiérrez \& Goyache, 2005) foi utilizado para análise do pedigree e estimação dos parâmetros populacionais baseados na probabilidade de origem do gene, no tamanho efetivo e no intervalo de gerações.

O tamanho efetivo da população $(\mathrm{Ne})$ foi estimado por meio da taxa de variação dos coeficientes médios de endogamia entre gerações sucessivas, conforme equação a seguir:

$\Delta F=\frac{F_{t}-F_{t-1}}{1-F_{t-1}}$, com rearranjos $N_{e}=\frac{1}{2 \Delta F}$, em que: $\mathrm{F}_{\mathrm{t}}=$ coeficiente médio de endogamia estimando na geração atual; $\mathrm{F}_{\mathrm{t}-1}=$ coeficiente médio de endogamia estimado na geração anterior.

O número efetivo de fundadores representa o número de animais com igual contribuição que produziria a mesma variabilidade genética encontrada na população estudada. O número efetivo de ancestrais representa o número mínimo de animais (fundadores ou não) necessário para explicar a total diversidade genética da população estudada (Gutiérrez \& Goyache, 2005).

As estatísticas de $\mathrm{F}$ de Wright (1978), $\mathrm{F}_{\mathrm{it}}, \mathrm{F}_{\mathrm{st}}$ e $\mathrm{F}_{\mathrm{is}}$, foram calculadas por meio do software ENDOG (Gutiérrez \& Goyache, 2005). Fit é o coeficiente médio de endogamia da população, $\mathrm{F}_{\mathrm{st}}$ designa o coeficiente médio de endogamia esperado se os reprodutores de cada período fossem acasalados aleatoriamente e foi estimado em populações hipotéticas produzidas pelo acasalamento ao acaso dos pais dentro de cada período e $\mathrm{F}_{\text {is }}$ expressa $\mathrm{o}$ desvio da casualidade obtida nos acasalamentos atuais. Se $\mathrm{F}_{\text {is }}>0$, então a endogamia real ultrapassa o nível esperado sob acasalamentos ao acaso, implicando que os acasalamentos estão acontecendo entre animais mais aparentados que a média, consequentemente, a população estará dividida em subpopulações. Quando $\mathrm{F}_{\text {is }}<0$, evita-se a endogamia ou predomina o acasalamento entre subpopulações.

\section{Resultados e Discussão}

As médias ( \pm desvio-padrão) e os coeficientes de variação (CV) para os pesos aos 205 (P205), 365 (P365) e 550 (P550) dias de idade foram de 165,25 \pm 37,42 kg e 22,65\%; $237,69 \pm 54,11$ kg e $22,78 \%$; 305,33 $\pm 75,70$ kg e $24,79 \%$, respectivamente.

As estimativas dos coeficientes de herdabilidades direta $(0,11 \pm 0,03)$ e materna $(0,01 \pm 0,03)$ para o $\mathrm{P} 205$ foram baixas (Tabela 2). Para o P365 e P550, os coeficientes de herdabilidade (efeito direto) foram ligeiramente superiores: $0,16 \pm 0,04 ; 0,150,05$, respectivamente.

Malhado et al. (2005a), estudando animais da raça Nelore Mocho no estado da Bahia, relataram coeficientes de herdabilidade maiores: 0,24 $\pm 0,04$ e 0,20 $\pm 0,06$, para o efeito direto e materno, respectivamente. Lôbo et al. (2000), com base em 78 trabalhos de bovinos, observaram herdabilidade média de 0,30 para o efeito direto de P205 enquanto Gianotti et al. (2005) relataram herdabilidade média de 0,23 ao revisarem 331 trabalhos com bovinos.

Os coeficientes de herdabilidade estimados para efeito direto de P365 e P550 foram menores que os observados em estudos com diferentes raças zebuínas. Lôbo et al. (2000) observaram herdabilidades médias de 0,37 e 0,35 para o efeito direto de P365 e P550, respectivamente. Gianotti et al. (2005) relataram herdabilidades médias de 0,27 e 0,31, na mesma ordem, para P365 e P550. Lira et al. (2008), revisando 67 trabalhos com zebuínos, encontraram estimativas médias de herdabilidade direta de 0,31 e 0,35 para P365 e P550, respectivamente.

Neste trabalho, os coeficientes de herdabilidade do efeito genético direto para peso nas três idades foram menores que os observados na literatura para outras raças zebuínas, o que indica menor variabilidade genética aditiva direta para o Indubrasil no nordeste brasileiro

Tabela 2 - Estimativas dos componentes de variâncias e herdabilidades para os pesos aos 205 (P205), 365 (P365) e 550 (P550) dias de idade em bovinos da raça Indubrasil do Nordeste brasileiro ${ }^{1}$

\begin{tabular}{lccccccc}
\hline & $\sigma_{a}{ }^{2}$ & $\sigma_{m}{ }^{2}$ & $\sigma_{e p}{ }^{2}$ & $\sigma_{e}{ }^{2}$ & $\sigma_{p}{ }^{2}$ & $h^{2}{ }_{d}$ & $h^{2}{ }_{m}$ \\
\hline P205 & 65,29 & 5,92 & 37,26 & 481,35 & 589,83 & $0,11 \pm 0,03$ & $0,01 \pm 0,03$ \\
P365 & 168,65 & - & - & 894,90 & 1063,56 & $0,16 \pm 0,04$ & - \\
P550 & 241,45 & - & - & 1415,72 & 1657,17 & $0,15 \pm 0,05$ & - \\
\hline
\end{tabular}

(1) $\sigma^{2} ; \sigma_{\mathrm{m}}^{2} ; \sigma^{2}{ }_{\mathrm{ep}} ; \sigma^{2}{ }_{\mathrm{e}} ; \sigma^{2} ; \mathrm{h}_{\mathrm{d}}^{2} ; \mathrm{h}^{2}{ }_{\mathrm{m}}$ são, respectivamente, estimativas dos componentes de variância genética aditiva direta, genética aditiva materna, variância de ambiente permanente, variância residual, variância fenotípica, herdabilidades direta e herdabilidade materna. 
e evidencia menor oportunidade de ganho genético com a seleção para peso nesta raça. O coeficiente de herdabilidade materna para P205 foi extremamente baixo, o que sugere grande influência do meio ambiente sobre o peso à desmama e dificuldade de ganho genético para essa característica por meio de seleção para efeito materno.

$\mathrm{O}$ estudo da tendência genética permite avaliar a mudança provocada pelo processo seletivo em determinada característica ao longo dos anos. Para a característica P205, a tendência genética para o efeito direto, estimada pela regressão linear, foi significativa $(\mathrm{P}<0,01)$, com valor
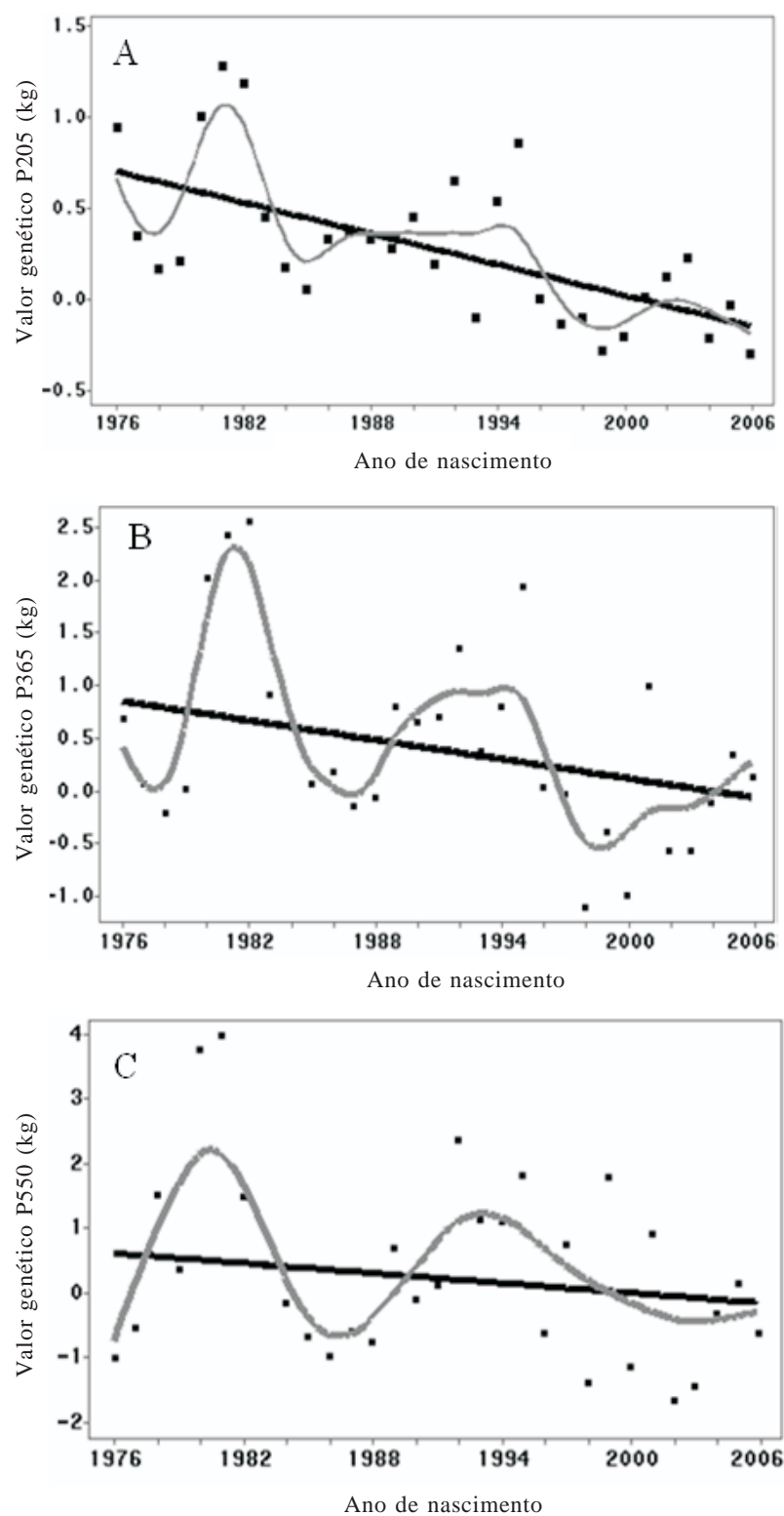

Figura 1 - Tendência genética para o efeito direto das características P205(A), P365 (B) e P550 em bovinos da raça Indubrasil do Nordeste brasileiro. estimado de -0,028 kg/ano (Figura 1), representando redução de 3,33\% na média do peso à desmama por ano. Malhado et al. (2005a) também relataram tendências genéticas negativas $(\mathrm{P}<0,05)$ para $\mathrm{P} 205$, com valor estimado de $-0,07 \mathrm{~kg} / \mathrm{ano}$ para o efeito direto em bovinos da raça Nelore Mocho no estado da Bahia.

Malhado et al. (2008b), no entanto, encontraram tendência genética positiva para o peso ao desmame estudando bovinos da raça Nelore no estado da Bahia. A tendência genética (regressão linear) do efeito direto foi significativa $(\mathrm{P}<0,001)$ e igual a $0,049 \mathrm{~kg} / \mathrm{ano}$, o que representou progresso genético de $1,76 \mathrm{~kg}$, nos 36 anos analisados.

Para os pesos aos 365 e 550 dias de idade, as tendências genéticas (regressão linear) para o efeito direto não foram significativas $(\mathrm{P}>0,05)$, e as estimativas foram iguais a $-0,030$ e $-0,025 \mathrm{~kg} / \mathrm{ano}$, respectivamente (Figura 1), o que indica que, para os pesos a essas idades, não houve alteração nos valores genéticos dos animais da raça Indubrasil criados no Nordeste durante o período avaliado.

Biffani et al. (1999) frisaram que, nas condições de criação típicas do Nordeste, os criadores selecionam os animais mais por suas características anatômicas e raciais que pelo seu desempenho produtivo. Esse fato, associado a cruzamentos desordenados, falhas na orientação técnica e pequena utilização de animais avaliados geneticamente, refletem na tendência genética negativa ou nula para peso na raça Indubrasil. Outras raças zebuínas, como a Nelore, têm mostrado pequeno progresso genético nos últimos anos, como pode ser observado por Malhado et al. (2005b), que relataram existência de pequeno ganho genético nos últimos dez anos para características relacionadas à velocidade de crescimento em bovinos da raça Nelore em toda região Nordeste.

A tendência fenotípica (regressão linear) para o peso aos 205 dias de idade (P205) foi significativa $(P<0,01)$ e igual a 0,50 kg/ano. Já para P365 e P550, as tendências fenotípicas não foram significativas $(\mathrm{P}>0,05)$ e foram iguais a 0,32 e 0,69 kg/ano, respectivamente. Esses resultados mostram que a característica P205 melhorou no decorrer dos anos, evidenciando que os produtores estão conseguindo ganhos fenotípicos anuais significativos no crescimento dos animais até a desmama. Entretanto, esse pequeno progresso é devido, principalmente, a condições ambientais, visto que a contribuição genética foi negativa.

O número de animais nascidos por ano da raça Indubrasil no nordeste brasileiro vem diminuindo 
drasticamente nas duas últimas décadas, evidenciando um desinteresse dos criadores por animais desta raça. $\mathrm{Na}$ Figura 2 observa-se que o número de animais nascidos foi muito pequeno até 1975 (menor que oito animais por ano). A partir de 1976, o número de nascimentos aumentou, atingindo o maior valor em 1987 (964 nascimentos por ano). Depois desse ano, o número de nascimentos diminuiu chegando a apenas 47 nascimentos registrados em 2007.

As estimativas do intervalo de gerações para as quatro passagens gaméticas, para todo o pedigree dos bovinos Indubrasil, foram 6,91 $\pm 2,81$ (pai-filho), 6,84 $\pm 2,74$ (pai-filha), 7,62 $\pm 3,17$ (mãe-filho), 7,53 $\pm 3,21$ anos (mãe-filha), com intervalo médio de 7,23 $\pm 2,99$ anos. Os intervalos de geração do Indubrasil da Região Nordeste são muito grandes e próximos aos observados no rebanho nacional. Vercesi Filho et al. (2002b) avaliando a estrutura populacional do Indubrasil registrado no Brasil, observaram intervalos de 7,32 (pai-filho), 7,64 (pai-filha), 7,43 (mãe-filho) e 7,72 anos (mãe-filha), com média de 7,53 anos.

Outros estudos sobre intervalos de geração em rebanhos zebuínos registrados criados no Brasil mostraram valores médios semelhantes aos encontrados para a raça Indubrasil da Região Nordeste (6,56 anos no Gir Mocho, Faria et al., 2001a; 7,09 anos no Nelore Mocho, Faria et al., 2002; 7,17 anos no Tabapuã, Vercesi Filho et al., 2002a; 8,02 anos no Gir, Queiroz \& Lôbo, 1993).

O intervalo médio de gerações é fundamental em um programa de seleção, pois intervalos muito grandes diminuem o ganho genético anual para as características selecionadas, o que reduz o retorno econômico do programa. Intervalos de geração muito menores são possíveis de ser alcançados. Um exemplo são os rebanhos de seleção da Estação Experimental de Zootecnia de

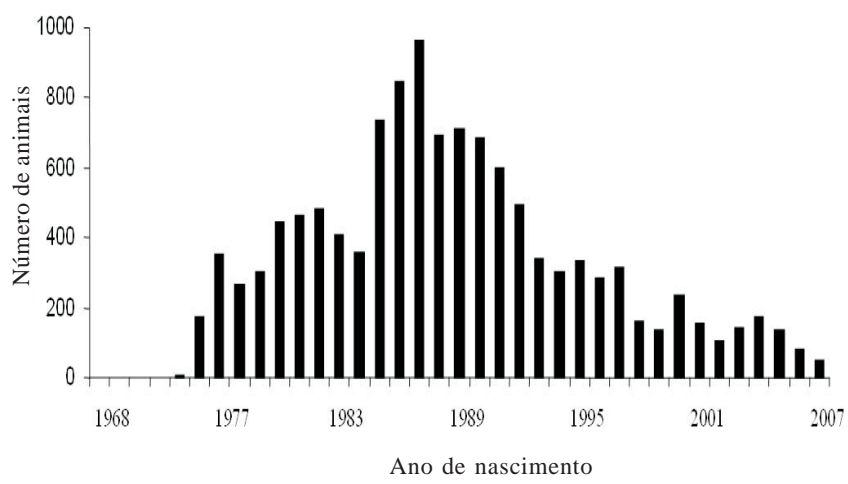

Figura 2 - Número de animais nascidos da raça Indubrasil do Nordeste brasileiro no período de 1968 a 2007.
Sertãozinho, São Paulo, onde os intervalos pai-filhos foram 3,66 e 3,74 anos para as raças Nelore e Guzerá, respectivamente (Razook et al., 1993).

O tamanho efetivo (Figura 3) aumentou do período 1956-1962 até o 1986-1992, quando atingiu o maior valor (292). A partir desse período, o tamanho efetivo caiu até o último período avaliado, atingindo o valor de 26. Do período 1968-1974 para o 1980-1986, apesar de o número de touros ter aumentado $47,5 \%$ e de vacas $61,14 \%$, o acréscimo do tamanho efetivo foi de apenas 31,53\%. A explicação para a redução do tamanho efetivo na raça Indubrasil do Nordeste está relacionada, principalmente, à diminuição do número de touros e vacas usados na reprodução nas duas últimas décadas e ao aumento do número médio de filhos por ano dos touros, que tem se mantido em torno de 5 desde o período 1968-1974.

Valor muito baixo de tamanho efetivo foi observado também por Faria et al. (2001b), que avaliaram parâmetros populacionais do rebanho Sindi do Brasil e encontraram tamanho efetivo de 19 no último período avaliado (19941998) e concluíram que o rebanho Sindi apresenta sério risco de desaparecimento no Brasil.

Vercesi Filho et al. (2002b) encontraram tamanho efetivo de 42 para o rebanho Indubrasil registrado no Brasil no período 1994-1998. O tamanho efetivo de 26, observado no último período para a raça Indubrasil do nordeste é bem inferior ao encontrado para o rebanho nacional, podendo ser considerado de risco, e também é bem menor que os valores encontrados, nos últimos períodos de avaliação para outras raças zebuínas criadas no Brasil: $\mathrm{Ne}_{\text {Nelore Mocho }} 124$ (Faria et al., 2002); $\mathrm{Ne}_{\text {Tabapuã }}=55$ (Vercesi Filho et al., 2002a) e $\mathrm{Ne}_{\text {Gir Mocho }}=70$ (Faria et al., 2001a).

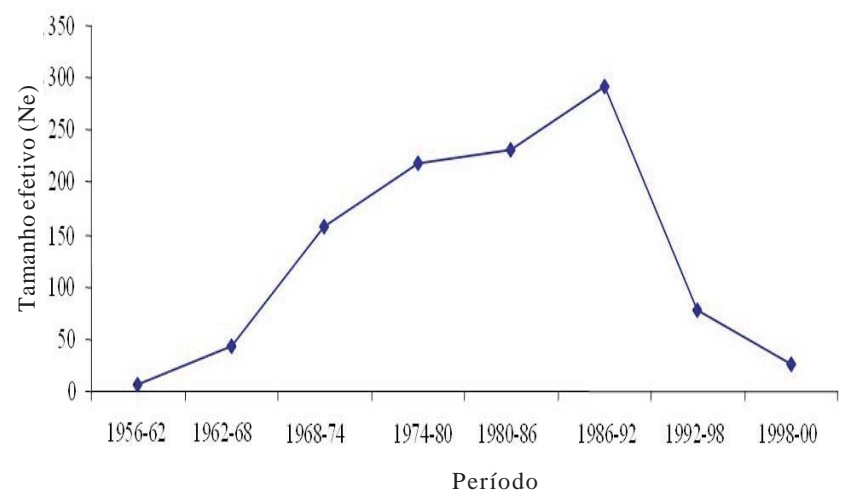

Figura 3 - Tamanho efetivo no período de 1956 a 2000 em bovinos da raça Indubrasil do Nordeste brasileiro. 
Tamanho efetivo mínimo de 40 animais por geração foi sugerido por Goddard \& Smith (1990), para aumentar o retorno econômico, enquanto Meuwissen \& Woolliams (1994) recomendaram valores entre 31 e 250 animais para prevenir decréscimos no valor adaptativo da população. Frankham (1995), por sua vez, sugeriu tamanho efetivo da ordem de 500 animais para manutenção do potencial evolutivo indefinidamente, contudo, frisou que, para a prevenção de depressão endogâmica, tamanho efetivo de 50 animais seria suficiente. Para populações sob conservação, um tamanho efetivo mínimo de 50 também é recomendado pela FAO (1998).

O coeficiente de endogamia médio estimado para as seis gerações passou de $0,95 \%$ na segunda geração para $7,37 \%$ na sexta. Os aumentos do coeficiente de endogamia foram maiores nas últimas gerações, quando atingiram maior valor (3,05\%) da geração 5 para 6 . Faria et al. (2004) consideraram crítico o coeficiente de endogamia para a raça Sindi no Brasil, tendo atingindo no período de 1994 a 1998 (10,13\%), com crescimento da ordem de 33 vezes em relação ao valor do primeiro período avaliado (19791983). Silva et al. (2001) analisaram registros de animais do ecótipo Mantiqueira e observaram que os níveis médios do coeficiente de endogamia por geração oscilaram de 0,33 a 7,34, com crescimento até a última geração. Neste trabalho a endogamia influenciou de maneira negativa as características produção de leite e duração da lactação e aumentou a idade ao primeiro parto e o intervalo de partos. Queiroz et al. (2000) avaliaram o efeito da endogamia e suas possíveis influências sobre o crescimento de bovinos de corte da raça Gir. Apenas 11,65\% das vacas, 19,84\% dos touros e $9,23 \%$ dos bezerros da raça Gir estudados apresentaram algum grau de endogamia e as estimativas das médias de endogamia foram de pequena magnitude, constatando-se valores de 1,04; 0,96; e 1,66\% para vacas, touros e bezerros, respectiva-mente. Os resultados mostraram depressão endogâmica para ambas as características (P205 e P365).

O aumento da endogamia média na raça Indubrasil da Região Nordeste, principalmente nas últimas décadas, é um reflexo da redução do tamanho dos rebanhos, constatada pela redução de nascimentos por ano (Figura 2), além da utilização de poucos animais para a reprodução. A taxa elevada de endogamia refletiu em ganhos genéticos negativos e nulos para peso nas diferentes idades (Figura 1) e em grande redução do tamanho efetivo da população (Figura 3).

Do total de 17.057 animais, 5.494 tinham pelo menos um pai não conhecido. O número total de animais na população-referência, aquela em que os animais têm ambos os pais conhecidos, foi de 11.469. Desta forma, o número de animais com ambos os pais desconhecidos foi de apenas 94. A contribuição genética dos 10 e 37 fundadores mais influentes explica, na mesma ordem, 9,36 e 21,60\% da variabilidade genética de toda população. Para explicar 50\% da variabilidade genética da população, foram necessários apenas 225 ancestrais (fundadores ou não).

As estimativas para as estatísticas F de Wright para a população de Indubrasil no Nordeste foram: $\mathrm{F}_{\mathrm{it}}=0,0032$; $\mathrm{F}_{\mathrm{st}}=0,0185$ e $\mathrm{F}_{\text {is }}=-0,0156$. A estatística $\mathrm{F}_{\text {is }}$, que mede o desvio da casualidade nos acasalamentos, foi negativa e próxima a zero, revelando pequeno predomínio de acasalamentos entre subpopulações, o que contribuiu para reduzir a endogamia. Quando a Fis é menor que zero, estaria ocorrendo um processo em que se procura evitar o acasalamento entre subpopulações, o que pode estar associado, neste estudo, à grande utilização de reprodutores próprios nos rebanhos multiplicadores e comerciais (em torno de $80 \%)$.

O baixo valor de $\mathrm{F}_{\mathrm{st}}$ indica ausência de estruturação da população, fato confirmado pela classificação dos rebanhos (Tabela 3), uma vez que $100 \%$ dos rebanhos utilizam touros externos e/ou inseminação artificial e que $76 \%$ deles vendem touros. Neste estudo nenhum rebanho foi classificado como núcleo (rebanhos que não utilizam reprodutores externos e vendem reprodutores) ou sem ligação (isolado). Os rebanhos, em sua maioria (76\%), foram classificados como multiplicador (utilizam reprodutores externos ou próprios e vendem reprodutores) e 26\% como comercial (utilizam reprodutores externos ou próprios e não vendem reprodutores). Na raça Indubrasil no Nordeste,

Tabela 3 - Classificação dos rebanhos registrados dos bovinos Indubrasil do Nordeste de acordo com a origem e uso dos touros

\begin{tabular}{lccccc}
\hline Tipo de rebanho & $\begin{array}{c}\text { Utilizam touros } \\
\text { externos }\end{array}$ & $\begin{array}{c}\text { Utilizam touros } \\
\text { próprios }\end{array}$ & $\begin{array}{c}\text { Vendem } \\
\text { touros }\end{array}$ & $\begin{array}{c}\text { Número de } \\
\text { rebanhos }\end{array}$ & $\begin{array}{c}\text { Percentagem touros } \\
\text { externos }\end{array}$ \\
\hline Núcleo & Não & Sim & Sim & 0 & 0 \\
Multiplicador & Sim & Sim & Sim & 45 & 47,13 \\
Multiplicador & Sim & Não & Sim & 12 & 100 \\
Comercial & Sim & Sim & Não & 30,65 \\
Comercial & Sim & Não & Não & 16 & 0 \\
Isolado & Não & Sim & Não & 0 & 0 \\
\hline
\end{tabular}


é preocupante a frequente utilização de reprodutores próprios nos rebanhos multiplicadores e comerciais (em torno de $80 \%$ ), porém esse elevado índice não foi suficiente para levar à subdivisão da população. A subdivisão ou estruturação da população pode ocorrer por meio de subpopulações com limitada migração e fluxo gênico entre elas, podendo resultar em subpopulações totalmente isoladas agravando os problemas de conservação de grupos genéticos.

Vercesi Filho et al. (2002b), utilizando registros genealógicos de animais Indubrasil de todo o território nacional, observaram resultados bem diferentes. Esses autores registraram um processo de subdivisão na raça indubrasil, ocasionado pela baixa utilização de inseminação artificial aliada à baixa intensidade de seleção e postularam que as subpopulações estariam sendo formadas regionalmente.

Os resultados encontrados neste trabalho destacam que os ganhos genéticos para as características de desenvolvimento ponderal da raça Indubrasil no Nordeste decresceram ou foram nulos no período de 1964 a 2006. Estes resultados estão relacionados a fatores que comprometem a conservação e expansão da raça, como redução do tamanho efetivo da população, aumento da endogamia, oscilação genética e redução da variabilidade genética. Segundo Carneiro et al. (2007b), com o uso de populações com pequenos tamanhos efetivos em processos seletivos, os resultados podem ser muito influenciados pela oscilação genética, podendo ocasionar grandes variações nos ganhos genéticos.

O modismo na pecuária de corte tem causado sérios problemas. Raças surgem, passam a ser utilizadas intensivamente, mesmo sem avaliação genética adequada, e posteriormente deixam de ser utilizadas e passam a correr risco de extinção, necessitando assim de programas de conservação genética e de medidas objetivas que visem a sua utilização futura.

\section{Conclusões}

A raça Indubrasil do Nordeste brasileiro apresenta graves problemas em sua estrutura populacional e não sofreu progresso genético nas três características avaliadas desde 1976. A redução no número de nascimentos por ano e a pouca utilização de reprodutores externos nos rebanhos colocam essa raça como um grupo genético em risco de extinção, o que tornam necessários programas visando sua conservação e expansão.

\section{Literatura Citada}

BERRY, S.M.; CARROLL, R.J.; RUPPERT, D. Bayesian smoothing and regression splines for measurement error problems. Journal of the American Statistical Association, v.97, n.457, p.160 169, 2002.

BIFFANI, S.; MARTINS FILHO, R.; GIORGETTI, A. et al. Fatores ambientais e genéticos sobre o crescimento ao ano e ao sobreano de bovinos Nelore, criados no Nordeste do Brasil. Revista Brasileira de Zootecnia, v.28, p.468-473, 1999.

BOLDMAN, K.G.; KRIESE, L.A.; VAN VLECK, L.D. et al. A manual for use of MTDFREML; a set of programs to obtain estimates of variances and covariances [DRAFT]. Lincoln: Department of Agriculture, Agricultural Research Service, 1995. $120 \mathrm{p}$.

CARNEIRO, T.X.; GONÇALVES, E.C.; SCHNEIDER, M.P.C. et al. Diversidade genética e eficiência de DNA microssatélites para o controle genealógico da raça Nelore. Arquivo Brasileiro Medicina Veterinária Zootecnia, v.59, p.1257-1262, 2007a.

CARNEIRO, P.L.S.; MALHADO, C.H.M.; EUCLIDES, R.F. et al. Oscilação genética em populações submetidas a métodos de seleção tradicionais e associados a marcadores moleculares. Revista Brasileira de Zootecnia, v.35, p.84-91, 2007b.

CAROLINO, N.; GAMA, L.T. Indicators of genetic erosion in an endangered population: The Alentejana cattle breed in Portugal. Journal of Animal Science, v.86, p.47-56, 2008

CLEVELAND, M.A.; BLACKBURN, H.D.; ENNS, R.M. et al. Changes in inbreeding of U.S. Herefords during the twentieth century. Journal of Animal Science, v.83, p.992-1001, 2005.

CURI, R.A.; LOPES, C.R. Evaluation of nine microsatellite loci and misidentification paternity frequency in a population of Gyr breed bovines. Brazilian Journal of Veterinary Research and Animal Science, v.39, p.129-135, 2002.

EGITO, A.A.; FUCK, B.; SPRITZE, A.L. et al. Uso de marcadores rapd en la formación o mantenimiento de núcleos de conservación de animales domésticos. Archivos de Zootecnia, v.54, p.277-281, 2005.

EGITO, A.A.; FUCK, B.; MCMANUS, C.M. et al. Genetic variability of Pantaneiro horse using RAPD-PCR markers. Revista Brasileira de Zootecnia, v.36, p.799-806, 2007a.

EGITO, A.A.; PAIVA, S.R.; ALBUQUERQUE, M.S.M. et al. Microsatellite based genetic diversity and relationships among ten creole and commercial cattle breeds raised in Brazil. BMC Genetics (Online), v.8, p.83, 2007b.

EUCLIDES FILHO, K.; SILVA, L.O.C.; ALVES, R.G.O. et al. Tendência genética na raça Gir. Pesquisa Agropecuária Brasileira, v.35, p.787-791, 2000.

FOOD AND AGRICULTURE ORGANIZATION - FAO. [1998]. Secondary guidelines for development of national farm animal genetic resources management plans. Management of small populations at risk. In: WOOLLIAMS, J.A.; GWAZE, G.P.; Meuwissen, T.H.E. et al. (Eds.) Food and Agriculture Organization of the United Nations. Online. Disponível em: <http://dad.-fao.org/en/refer/library/guidelin/ sml-popn.pdf.>. Acesso em: 19/6/2008.

FARIA, F.J.C.; VERCESI FILHO, A.E.; MADALENA, F.E. et al. Parâmetros populacionais do rebanho Gir Mocho registrado no Brasil. Revista Brasileira de Zootecnia, v.30, p.1984-1988, 2001a (supl.).

FARIA, F.J.C.; VERCESI FILHO, A.E.; MADALENA, F.E. et al Parâmetros populacionais do rebanho Sindi registrado no Brasil. Revista Brasileira de Zootecnia, v.30, p.1989-1994, 2001b (supl.).

FARIA, F.J.C.; VERCESI FILHO, A.E.; MADALENA, F.E. et al. Estrutura populacional da raça Nelore Mocho. Arquivo Brasileiro de Medicina Veterinária e Zootecnia, v.54, p.501-509, 2002. 
FARIA, F.J.C.; VERCESI FILHO, A.E.; MADALENA, F.E. et al. Estrutura genética da raça Sindi no Brasil. Revista Brasileira de Zootecnia, v.33, p.852-857, 2004.

FERRAZ FILHO, P.B.; RAMOS, A.A.; SILVA, L.O.C. et al. Tendência genética dos efeitos diretos e maternos sobre os pesos à desmama e pós-desmama de bovinos da raça tabapuã no Brasil. Revista Brasileira de Zootecnia, v.31, p.637-642, 2002.

FRANKHAM, R. Conservation genetics. Annual Review of Genetics, v.29, p.305-327, 1995.

GANGULI, B.; STAUDENMAYER, J.; WAND, M.P. Additive Models with predictors subject to measurement error. Australian New Zealand Journal Statistical, v.47, n.2, p.193-202, 2005.

GIANNOTTI, J.F.G.; PACKER, I.U.; MERCADANTE, M.E. Metaanálise das estimativas de herdabilidade para características de crescimento em bovinos de corte. Revista Brasileira de Zootecnia, v.34, n.4, p.1173-1180, 2005

GODDARD, M.G.; SMITH, C. Optimum number of bull sires in dairy cattle breeding. Journal of Dairy Science, v.73, p.11131122, 1990

GUTIÉRREZ, J.P.; GOYACHE, F. A note on ENDOG: a computer program for monitoring genetic variability of populations using pedigree information. Journal of Animal Breeding and Genetics, v.122, p.172-176, 2005.

GUTIÉRREZ, J.P.; MARMI, J.; GOYACHE, F. et al. Pedigree information reveals moderate to high levels of inbreeding and a weak population structure in the endangered Catalonian donkey breed. Journal of Animal Breeding and Genetics, v.122, p.378-386, 2005.

LIRA, T.; ROSA, E.M.; GARNERO, A.D.V. parâmetros genéticos de características produtivas e reprodutivas em zebuínos de corte (revisão). Ciência Animal Brasileira, v.9, p.1-22, 2008.

LÔBO, R.N.B.; MADALENA, F.E.; VIEIRA, A.R. Average estimates of genetic parameters for beef and dairy cattle in tropical regions. Animal Breeding Abstracts, v.68, n.6, p.433-461, 2000.

MACHADO, M.A.; SHUSTER, I.; MARTINEZ, M.L. et al. Diversidade genética de quatro raças bovinas utilizando marcadores microssatélites. Revista Brasileira de Zootecnia, v.32, p.93-98, 2003.

MALHADO, C.H.M.; CARNEIRO, P.L.S.; MARTINS FILHO, R. et al. Tendência e parâmetros genéticos para o peso aos 205 dias de idade em bovinos da raça Nelore Mocho no estado da Bahia. Revista Científica de Produção Animal, v.7, p.28-34, 2005a.

MALHADO, C.H.M.; MARTINS FILHO, R.; LÔBO, R.N.B. et al. Tendência genética sobre características relacionadas à velocidade de crescimento de bovinos nelore na região Nordeste do Brasil. Revista Brasileira de Zootecnia, v.34, p.60-65, 2005b.

MALHADO, C.H.M.; RAMOS, A.A.; CARNEIRO, P.L.S. et al. Melhoramento e estrutura populacional em bubalinos da raça Mediterrâneo no Brasil. Pesquisa Agropecuária Brasileira, v.43, p.215-220, 2008a.

MALHADO, C.H.M.; RAMOS, A.A.; CARNEIRO, P.L.S. et al. Progresso genético e estrutura populacional do rebanho Nelore no estado da Bahia. Pesquisa Agropecuária Brasileira, v.43, p.1163-1169, 2008b.

MARTÍNEZ, R.A.; GARCÍA, D.; GALLEGO, J.L. et al. Genetic variability in Colombian Creole cattle populations estimated by pedigree information. Journal of Animal Science, v.86, p.545-552, 2008.

MEUWISSEN, T.H.E.; WOOLLIAMS, J. Effective sizes of livestock populations to prevent a decline in fitness. Theoretical and Applied Genetics, v.89, p.1019-1026, 1994.
NOMURA, T.; HONDA, T.; MUKAI, F. Inbreeding and effective population size of Japanese Black cattle. Journal of Animal Science, v.79, p.366-370, 2001.

OLIVEIRA, J.A.; LÔBO, R.B.; NUNES, H.O. Tendência genética em pesos e ganhos de pesos em bovinos da raça Guzerá. Pesquisa Agropecuária Brasileira, v.30, n.11, p.1355-1360, 1995.

PARLAND, S.Mc.; KEARNEY, J.F.; RATH, M. et al. Inbreeding trends and pedigree analysis of Irish dairy and beef cattle populations. Journal of Animal Science, v.85, p.322-331, 2007.

POSTIGLIONI, A.G.; RINCÓN, L.K.; KELLY, L. et al. Biodiversidad genética en bovinos criollos del uruguay. análisis con marcadores moleculares. Archivos de zootecnia, v.51, p.195-202, 2002.

QUEIROZ, S.A.; LÔBO, R.B. Genetic relationship, inbreeding and generation interval in registered Gir cattle in Brazil. Journal of Animal Breeding Genetics, v.110, n.3, p.228-233, 1993.

QUEIROZ, S.A.; ALBUQUERQUE, L.G.; LANZONI, N.A. Efeito da endogamia sobre características de crescimento de bovinos da raça Gir no Brasil. Revista Brasileira de Zootecnia, v.29, n.4, p.1014-1019, 2000.

RANGEL, P.N.; ZUCCHI, M.I.; FERREIRA, M.E. Similaridade genética entre raças bovinas brasileiras. Pesquisa Agropecuária Brasileira, v.39, p.97-100, 2004.

RAZOOK, A.G.; FIGUEIREDO, L.A.; BONILHA NETO, L.M. et al. Intensidades de seleção e repostas diretas e correlacionadas em 10 anos de progênies de bovinos das raças Nelore e Guzerá selecionadas para peso pós desmame. Boletim Indústria Animal, v.50, n.2, p.147, 1993.

REINSCH, C. Smoothing by spline functions. Numerische Mathematik, v.10, p.177-183, 1967.

SANTIAGO, A.A. O Zebu na Índia, no Brasil e no mundo. Campinas: Instituto Campineiro de Ensino Agrícola, 1986. $744 p$.

SERRANO, G.M.; EGITO, A.A.; McMANUS, C. et al. Genetic diversity and population structure of Brazilian native bovine breeds. Pesquisa Agropecuária Brasileira, v.39, p.543-549, 2004.

SILVA, M.V.G.B.; FERREIRA, W.J.; COBUCI, J.A. et al. Efeito da endogamia sobre características produtivas e reprodutivas de bovinos do Ecótipo Mantiqueira. Revista Brasileira Zootecnia, v.30, p.1236-1242, 2001

SPRITZE, A.; EGITO, A.A.; MARIANTE, A.S. et al. Caracterização genética da raça bovina Crioulo Lageano por marcadores moleculares RAPD. Pesquisa Agropecuária Brasileira, v.38, p.1157-1164, 2003.

STATISTICAL ANALYSIS SYSTEM - SAS. User guide: Statistic. Cary: SAS Institute Inc., 1999. (CD-ROM)

VALERA, M.; MOLINA, A.; GUTIÉRES, J.P. et al. Pedigree analysis in the Andalusian horse: population structure, genetic variability and influence of the Carthusian strain. Livestock Production Science, v.95, p.57-66, 2005.

VERCESI FILHO, A.E.; FARIA, F.J.C.; MADALENA, F.E. et al. Estrutura populacional do rebanho Tabapuã registrado no Brasil. Arquivo Brasileiro de Medicina Veterinária e Zootecnia, v.54, p.609-617, 2002a.

VERCESI FILHO, A.E.; FARIA, F.J.C.; MADALENA, F.E. et al. Estrutura populacional do rebanho Indubrasil registrado no Brasil. Archivos Latinoamericanos de Producción Animal, v.10, p.86-92, 2002b.

WRIGHT, S. Evolution and the genetics of populations: Variability within and among natural populations. Chicago: University of Chicago Press, 1978. v.4, 590p. 